\title{
Advance Surveillance Robot using Raspberry Pilot
}

\section{G Sai Kiranmayi ${ }^{1} \mid$ B bhanu ${ }^{1} \mid$ B Manikanta ${ }^{1}$ | N Ashok ${ }^{1}$ | G Govinda Raju ${ }^{1}$}

${ }^{1}$ Department of ECE, VSM College of Engineering, Ramachandrapuram, AP, India.

\section{To Cite this Article}

G Sai Kiranmayi, B bhanu, B Manikanta, N Ashok and G Govinda Raju, "Advance Surveillance Robot using Raspberry Pilot", International Journal for Modern Trends in Science and Technology, Vol. 06, Issue 06, June 2020, pp.:54-57; https://doi.org/10.46501/IJMTST060613

\section{Article Info}

Received on 30-April-2020, Revised on 21-May-2020, Accepted on 28-May-2020, Published on 05-June-2020.

\section{ABSTRACT}

The main objective of this paper is to develop a virtual environment for detecting suspicious and targeted places for user without any loss of human life.The purpose of this project is to regulate robot with interface board of the raspberry pi, sensors and software to full fill real time equipment. There are sundry surveillance systems such as camera, CCTV etc. available in the market. In these systems, the person located in that particular area can only view what is transpiring in that place. We proposed a system to build an authentictime live streaming and monitoring system utilizing Raspberry pi with installed Wi-Fi connectivity. It can continuously monitor the objects. Robot can move in every direction (left, right,forward and backward). The webcam which is placed on the robotic unit will capture the video and it transmits vivacious to the remote end. The major application of this paper can be analysed utilizing HTML web page which can be acclimated to control the movement of the robot.

\section{KEYWORDS: Raspberrypi,Wi-Fi,HTMLPage, WebCam}

Copyright (c) 2014-2020 International Journal for Modern Trends in Science and Technology

DOI: https://doi.org/10.46501/IJMTST060613

\section{INTRODUCTION}

Earlier the robots were controlled through wired networks but now to form robot more users friendly, they're framed to form user commanded work. The robot is capable to work everywhere where there is a wireless connection. This project are often used for security purposes where we'd like to urge information about some suspicious area/people. We can do this by sitting at a far secure place and safely devise a plan to tackle their activities. It acquires image from cameras through a web browser. The robot contains a PC with a web server. It receives real-time uploaded image from cameras. As the internet of things is that the concept newly introduced within the field of electronics. The concept is about handling the items with the utilization of internet and therefore the best model for these applications is raspberry pi. When the surveillance is taken into account raspberry pi serve his purpose because it is sweet connectivity simply plugging Wi-Fi dongle into one among its port. On the other hand it can additionally be very auxiliary in explorers and animal psychologists need to optically canvass proximately the life style of sundry perilous animals like lions, snakes and diminutive insects so they utilize such kind of robots because human life is in jeopardy or their presence can perturb animal patterns of livings. Similarly it can be utilized in laboratories where hazardous chemicals and gases are tested. It can go to places where chemists can't go, check the 
leakage and additionally can perform other tasks. Similarly it can be used in laboratories where dangerous chemicals and gases are tested. It can check the leakage and also can perform other tasks. It is supported development of a robot vehicle for observing spying the suspicious objects. It can continuously monitor the objects. Robot can move in every direction (left, right, forward and backward).It is used for video surveillance and remotely control the particular place using Wi-Fi as medium. The webcam which is placed on the robotic unit will capture the video and it transmits lively to the remote end. The major application of this paper can be analysed using HTML web page which can be used to control the movement of the robot.L293D is quadruple dual H-Bridge motor driven IC.

\section{HARDWARE COMPONENTS}

\section{Raspberry Pi}

The Raspberry Pi 3 Model B is a third-generation Raspberry pi. This puissant, low cost and minuscule size single board computer can be utilized for many major and minor applications.

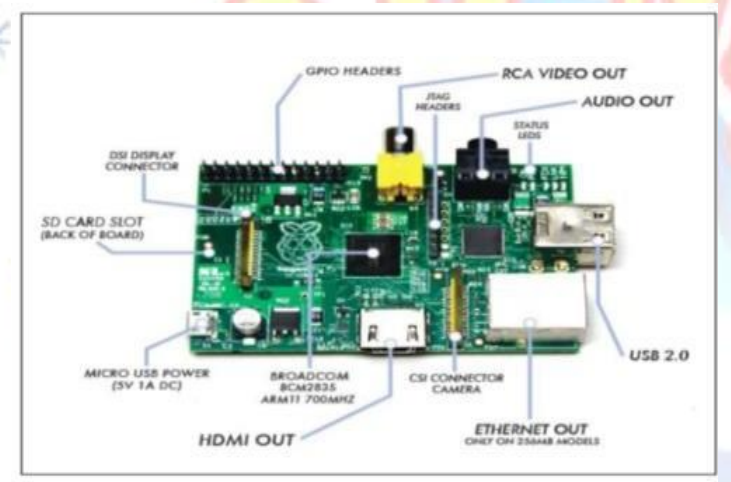

Fig: Raspberrypi

Raspberry pi 3 has most puissant processor and it is 10 times more expeditious than precedent generation. This third generation pi has adscititious wireless LAN and Bluetooth connectivity which is making it the ideal solution for puissant application. The Raspberry pi 3 contains many ports like camera connector, Ethernet port, GPIO pins which is mainly utilized for interfacing sensors and switches, USB port for external I/O contrivances, HDMI ports for monitor and audio jack port. These all are affixed with a single board. It does not have any internal storage or own operation system, but we can insert an SD card with Linux predicated OS.

\section{Raspberrypi camera:}

A Raspberry pi predicated camera is a video camera that victuals or streams an image or video in authentic time to or through a computer to a computer network, such as the Internet. Webcams are typically diminutive cameras that sit on a desk, affix to a utilizer's monitor, or are built into the hardware can be used during a video chat session involving two or more people, with conversations that include live audio and video.

\section{Wi-Fi:}

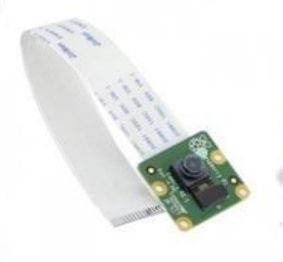

Fig:Camera

Wi-Fi networks haven't any physical wired connection between sender and receiver by using frequency (RF) technology -- a frequency within the spectrum related to radio emission propagation. When an RF current is supplied to an antenna, an electromagnetic field is made that then is in a position to propagate through space.

\section{ServoMotor:}

A unique design for servo motors are proposed in controlling and for control applications. They are fundamentally used to adjust the celerity control at high torques and precise situating. Components required are motor position sensor and a highly developed controller. These motors are often categorized according the servo motor controlled by servomechanism. If DC motor is controlled utilizing this mechanism, then it is denominated as a DC servo motor. Servo motors are available in power ratings from fraction of a watt to 100 watts. The rotor of a servo motor is designed longer in length and more minuscule in diameter so that it has low inertia. 


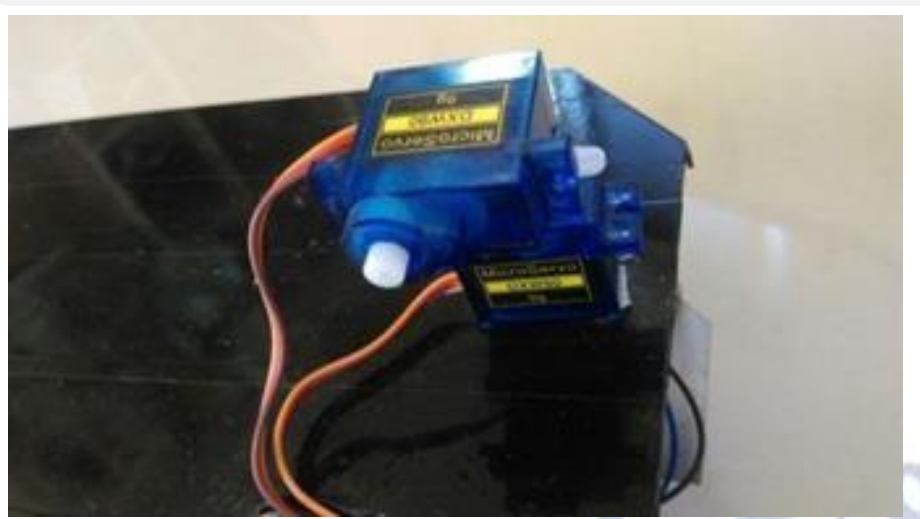

Fig:servo motor

\section{Motor:}

A DC motor is any of a category of rotary electrical motors that converts direct current electrical energy into mechanical energy. The most common types believe the forces produced by magnetic fields. Nearly all kinds of DC motors have some internal mechanism, either electromechanical or electronic to periodically change the direction of current partially of the motor. DC motors were the primary sort of motor widely used, as they might be powered from existing direct-current lighting power distribution systems.

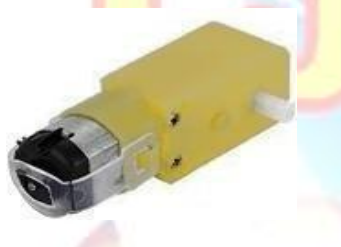

Fig:DC Motor

\section{L293D MotorDriver:}

L293D is a typical Motor driver or Motor Driver IC which allows DC motor to drive on either direction. L293D may be a 16-pin IC which may control a group of two DC motors simultaneously in any direction. It means you'll control two DC motor with one L293D IC. Dual H-bridge Motor Driver integrated circuit (IC).

\section{IMPLEMENTATION}

\section{Step-1:}

Testing of all Modules and sensor. Testing a module like raspberry pi camera, dc motor with L293D driver and servo motor with their respective programs.

\section{Step-2:}

Designing on software. To implement this project we make base of that robot For that purport with the avail of cad software we Done design of chasis

Step-3:

Installation of all the software.

$>$ Download the ZIP file of NOOBS Version 3.0.0. It is a large file and will take a while to complete. You will want Raspbian, so don't download NOOBS Lite.

$>$ Double-click on the NOOBS file from the Downloads folder in your Dock to open it

Select the first file inside the NOOBS folder.

$>$ Scroll down and Shift + left-click on the last file in the NOOBS folder.

$>$ Drag and drop all selected NOOBS files into the SD card icon on your desktop. You don't have to open the SD card drive

$>$ Right-click on the SD card icon. 7.Select "Eject [SD Card Name]".

$>$ Remove the card reader from your computer. 9.Remove the microSD card from the card reader

\section{Step-4:}

Designing a web page and creating cloud.The web page designing is main a part of our project to regulate robot from any remote area. It will be compulsory that to make one platform from there we will access our robot. From the web page we control the direction of motor and position of camera as well as monitor the video victual. It will be indispensable that make our web page secure from anyone. To make it secure we'll keep IP address highly confidencial. When sanctioned person want to get access on the robot he will be authenticate that page and enter the static IP address of raspberry pi and sanctioned utilizer get the access of that robot.

\section{IV.RESULT \& FUTURE SCOPE}

In this project we used raspberry pi working on Raspbian OS. As the communication is completed with the assistance of internet so limitation of range of operation doesn't arise and thus we will monitor any remote areas. One can easily monitor as well as control the activity of the robotic unit. 


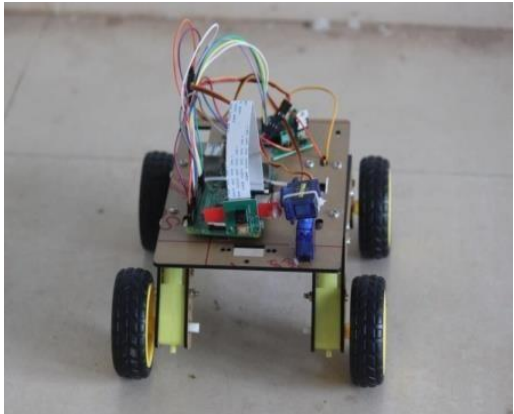

Fig: working model

The purpose of designing website is to regulate robot

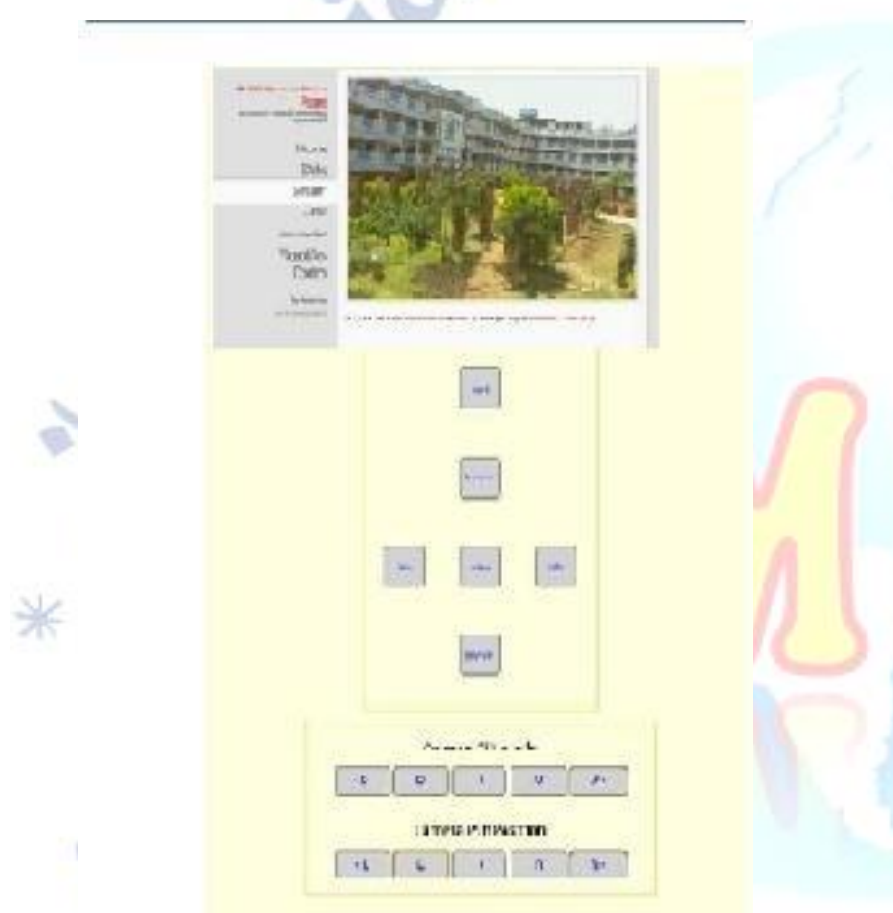

Fig:website design
Pressure Sensor, Heat Sensor, Position Sensor, Proximity Sensor. A multipurpose robot are often made by wireless network, starting from surveillance and residential security to industrial applications where the user needn't be present at the work place in person but can do it from his home itself. We can use this technique for military applications installing suitable sensors. Just by changing the robotic unit design we will use it in hospitals for patient monitoring. Using some chemical sensors we will detect harmful gas leakage within the chamber the time delay which occurs within the execution of commands are often reduced and thus we can have more real time access to the robot. With reduced time delay we will have faster operation and quick response to any illegal activities within the monitored area. Also it are often used as a spy robot. The robot is very economic.

\section{Acknowledgement:}

We are thankful to ECE Department of VSM College of Engineering Ramachandrapuram. We are very grateful to our Guider Prof. G.Govinda Raju who is support system of our Department.

\section{REFERENCES}

[1] Sandeep Bhatia, Mr. Ajay Mudgil, Ms. AmitaSoni, Alive Human Body Detection system using a Autonomous Mobile Rescue Robot, aspireacdemicexcellence.com 01/2011; DOI: $10.1109 /$ INDCON.2011.6139388

[2] K.Prema,N.Senthilkumar,S.S. Dash,S.SivaChandran, Online intelligent controlled mine detecting robot,International Journal of Computer Applications (0975 - 8887) Volume 41- No.17, March 2012

\section{CONCLUSION}

In this paper we implement a keenly intellective surveillance robot for military application with the avail of this robot we ken the authentic time condition of border area without utilizing a any human source. The surveillance robot gives us live streaming video consistent with that we give the command.

\section{Future Scope:}

There are lots of improvements that can be made on the current design and technology and lots of additional feature scan be added. We can use different types of sensor so that we can use robot in different field i.e. Temperature Sensor, 